Original Research Paper

\title{
Some Issues of Philosophical Analysis of the Materialistic World Views of Al-Biruni
}

\author{
Ernazarov Dilmurod Zukhriddinovich \\ Department of Social Sciences, Tashkent State University of Economics (TSUE), Uzbekistan
}

\author{
Article history \\ Received: 04-08-2020 \\ Revised: 02-12-2020 \\ Accepted: 16-12-2020 \\ Email: dilm79@inbox.ru
}

\begin{abstract}
The present article discusses certain works of the great Central Asian scientist-encyclopedic Abu Reikhan Mohammed ibn Ahmed Biruni which are becoming more and more accessible to scientists of various specialties and the figure of our famous compatriot seems to be more and more majestic. Biruni's legacy in various natural sciences has long been the subject of study by many scientists. The very first acquaintance with his works showed that they are of great philosophical significance. The ideological and materialistic worldview of Al Biruni has been analyzed in the article.
\end{abstract}

Keywords: India, Nature, Idealism, Materialism, Worldviews, Religion, Experiment, Philosophy

\section{Introduction}

The prominent eastern scholar Abu Raikhan Al-Biruni was one of the brightest representatives among the Central Asian scientists who led the process of the "Eastern Renaissance", which lasted for 7 centuries-from 800 to 1500. Scientists of this era were the greatest minds you've never heard of, but achievements that include the principles of algebra and trigonometry, the invention of the algorithm and the astrolabe, the foundations of modern medicine.

The study of the scientific heritage of Biruni has the following meanings for us.

First, the appeal of a modern researcher and historian of science to the heritage of representatives of the early medieval period has not lost its relevance because it has not yet been sufficiently studied. The work to identify the meanings of traditional philosophical concepts such as "nature", "time", "movement", "space", "root cause" and a description of the scientific achievements of the outstanding representative of the above-mentioned period of the Muslim East Biruni in this direction has not yet been completed: Comparative analysis and a parallel study of his achievements creates the basis for a constructive approach to the study of the problem of the philosophy of nature, for the revival of scientific and philosophical traditions, the foundations of which were laid by Biruni, at the present stage.

Secondly, the study of Biruni's natural philosophical views seems to be very timely in connection with the needs of a modern democratic society in the development of a scientific worldview, with the development of rational, secular and democratic projects, with the prospects for updating the philosophical and cultural values of each society. In this case, it will be possible to talk about the description of nature and its phenomena in the work of Biruni, not only limiting ourselves to those worldview standards that existed in the era of the thinker, but by those standards that were created on the basis of the ideas and theories put forward by him and which are in demand by our society Today. Natural philosophy is, in fact, a historical form of integrative thinking, very important for survival in a modern complex, global in nature, pluralistic world.

Thirdly, the study of "nature" in the writings of Biruni seems to be extremely timely in connection with the new perspectives of historical, philosophical and cultural reconstructions opening up to modern society. Along with a kind of historical heritage, the system of spiritual values includes the traditions and scientific methods that took place in the philosophical heritage of our ancestors, which play an important role in preserving the identity of the people in the education of the young generation.

Fourthly, the relevance of studying the natural philosophy of Biruni in a narrower sense for domestic science is that the time has come to acquaint the reader with the multifaceted heritage of our ancestors, philosophers and theorists of this period, whose work has not been sufficiently studied. 
Also, Russian scholar (Semenov, 1950) had written about this side of Biruni's legacy: "His works were distinguished by deep philosophical thought".

Academician I. Yu. Krachkovsky and others spoke about Biruni's great philosophical knowledge. V. Yu. Zakhidov's article "Biruniy as a thinker" (Zakhidov, 1950a) had been devoted to the philosophical views of Biruni. Some aspects of Biruni's philosophical views were discussed in the dissertation of (Faizullaev, 1962). Most foreign researchers of recognizing the philosophical significance of his works, heritage Biruni, see in them only "sincere religious convictions", "which made him a very attractive person".

This position was supported by such authors as Hilali, Courtois and others and in A. Sprenger's review of Biruni's "India" published by E. Zachau, the author even claims that Biruni had been a mystic. (Sprenger, 1986). Bourgeois scientists, who take idealistic positions, dwell on those aspects of Biruni's views that most of all correspond to their interests and their worldview. They did not take into account the real contradictions of that time, which were reflected in the views of the great learned thinker and cannot reveal the truly progressive aspects of his worldview. However, even those scientists were unable to completely obscure the enormous progressive significance of the general views of Biruni, as evidenced by the following statement of one of the American scientists: "Biruni had been so strict in his belief in reason and his disgust for everything unknown, incoherent, inconstant, or simply isolated, which resolutely turns to natural explanation, which relates an isolated phenomenon to something that includes several facts and principles. As a true scholar, Al-Biruni insisted on the need for observation and experiment and had contempt for anyone who had repeated tradition uncritically" (Arthur Upham Pope, 1951).

\section{Methodology and Analysis of Literature}

The article uses scientific methods such as systemic, comparative analysis, generalization, induction, deduction and also made a detailed analysis of a whole complex of objective factors that contribute to the identification of the true correlation of compared different religions, philosophical views, collection of reliable historical materials. Special attention was paid to the study of the conceptual-factual analysis of both Islamic and pre-Islamic beliefs of the peoples of India and Central Asia.

In writing the article, the following scientific works, articles and dissertations were analyzed:

1. Rozenfeld B.A., Rozhanskaya M.M., Sokolovskaya Z.K. Abu-r-Reikhan Al-Biruni (973-1048). -M.: Nauka, 1973
2. Mikhalina O.A. Philosophy of education of the West and the East: The need for development of intercultural dialogue//Analytics of cultural studies, 2009. № 15

3. Guseikhanov M.K. The contribution of thinkers of the Near and Middle East to the development of world science//Islamic Studies, 2011. No. 1

4. Umarova R.Sh. The life and philosophical views of Abu Raikhan Beruni//Achievements of Science and Education, 2019. No. 3 (44). S. 32-33

5. Karyeva A.K. The culture of the Turkic era in Central Asia and its contribution to the development of culture and education//Problems of modern science and education, 2017. No. 2 (84). S. 36-39

6. Madzhidov D. Natural philosophy of Abu Reikhan Biruni: Dissertation for the degree of candidate of philosophical sciences/Dushanbe, 2015

\section{Religion and Scientific Research of Al-Biruni}

One of the important goals of comparative analysis in religious studies is to overcome the false beliefs of adherents of some religions about others. Biruni emphasizes that much of what is written about the religions and beliefs of the Indians is "falsely attributed to them." Another, also no less important goal, is to clarify the false ideas of adherents of various sects and trends within one religion, in particular Islam, which arise in the course of its natural evolution and genesis.

The essential goal of comparative religious studies is determined by the process of changing religions among the same peoples, which Biruni himself repeatedly analyzes in his works, in particular "Monuments of past generations." Comparative study of religion, ultimately, can contribute to the improvement, clarification of the religion, the adherent of which is the researcher himself (Usmanov, 1973).

As the analysis of the complex of issues related to the problem of the comparative method in the works of Biruni shows, it essentially includes, not only his understanding of the purposes of applying this method but and means, mechanisms for its implementation. This is, first of all, an appeal to genuine written religious sources, which are preferred by "Yoga"; direct observation, communication, conversations with adherents of these religions; comparison of this information and messages; choosing the right basis for the comparison.

"When religious fanaticism swept medieval Europe... Al-Biruni, as a forerunner of the Renaissance, was far in advance of the scientific thought then obtaining in Europe" (Sparavigna, 2013).

The peculiar features of the Middle Ages, in which Biruni lived, was that religion and religious institutions found their expression and recognition in all manifestations of social life, "... church dogma was the 
starting point and basis of all thinking. Jurisprudence, natural science, philosophy is considered to be all the content of those sciences were brought into line with the teachings of the church" (Marx, 1962) and our task is to reveal in the views of Biruni that which objectively undermined religious beliefs and dogmas.

However, noting Biruni's adherence to the basic religious canons of Islam, his negative attitude to the ancient Greek and Eastern Peripatetic approach about the eternity of the world and time, some researchers of his work, such as Sayyid Hussein Nasr, try even more and artificially emphasize theological moments in his work and subdue all of his natural philosophy to religious dogmas, which does not correspond to the real state of affairs (Nasr, 1993).

\section{Biruni and the Theory of Atomism}

Biruni was considered to be primarily a naturalist. Studying natural phenomena, material reality, he takes the point of view of a spontaneously materialistic and naturalscientific explanation of them. But this is not surprising. We believe that every scientist, in practice, spontaneously takes the position of a natural explanation of natural phenomena, a materialistic approach to them.

But Biruni was a scientist-thinker. He did not limit himself to the position of a natural scientist, who spontaneously developed an attitude towards the world around him. Unlike such natural scientists, Biruni developed a method of scientific research, which was of great philosophical significance. One of the main provisions of this method was to strictly follow in its generalizations what is established in the process of experience, observation, experiment (Zakhidov, 1950b).

Naturally, Biruni did not always succeed in adhering to this method in his philosophical research. So, he recognized the existence of God, the creation of the world by God and the perfection of the world and other religious-idealistic provisions that did not at all follow from his scientific research and observations of the surrounding reality. This contradiction was characteristic of many scientists and philosophers of the Middle Ages, especially in the countries of Islam. But, Biruni set himself the task of following what follows from experience, from scientific research, or, in any case, agrees with them and this is the great merit of the great scientist. In his famous work "India" he says bluntly that his method is "inductive."

Biruni raises the question of the essence of the surrounding world for the first time and had its foundations in his polemic with Ibn Sina. It had been characteristic that he was not a shadow of doubt about the material basis of the surrounding world, of all nature. It follows from Biruni's statements that he had liked many philosophers and scientists of that time, recognized the existence of four elements that made up the whole nature around us-earth, water, fire, air. In turn, these elements were made up of atoms. Biruni's atomism, like the atomism of ancient Greek thinkers, was naturalphilosophical, i.e., the result of guesses, indirect conclusions, etc. In it, the essentially materialistic aspirations of the scientist in explaining the structure of the world find their expression.

Biruni considered the doctrine of the infinite divisibility of bodies to be untenable: "Why did Aristotle consider the doctrine of an indivisible particle to be flawed, while the assertion of the divisibility of bodies to infinity is even more flawed" (Uzbek SSR, 1957). At the same time, Biruni relied on Zeno's famous aporia to substantiate his position. But, on the other hand, Biruni asserted: "Many [controversial] statements were also inherent in atomists, well known among geometers ..." (Uzbek SSR, 1957).

Indeed, for the atomist philosophers, matter in the form of atoms and emptiness expressed, respectively, the principle of discontinuity (discreteness) and continuity, i.e., they had not yet considered the matter from the point of view of the dialectical unity of discontinuity and continuity. Curiously, atomism did not satisfy Biruni because of "[controversial] statements that are well known among geometers." Since for Biruni, geometric concepts were "forms abstracted from matter" (Biruni, 1963b), then by "[controversial] statements among geometers" he meant the interpretation of such concepts ("point", "line", etc.) that were not tied up with atomistic theory due to the fact that they assumed the infinite divisibility of bodies. Thus, Biruni was looking for a way out that would solve the contradictions of both theories, both atomism and the theory opposite to it. He objectively had seen the conclusions push him to reject the onesidedness of the two opposite theories. This in itself had already a great achievement for Biruni. The fact that he stood on this path, albeit unconsciously, spontaneously, as evidenced by the fact that, being an adherent of the atomistic theory, he considered the existence of emptiness optional, which at first glance does not fit in with the philosophical traditions of that time, since atomism then, as a rule, it assumed the recognition of the existence of emptiness, i.e., what was supposed to be continuity.

This suggests that he followed the path of recognizing two contradictory qualities at the same time material origin, but, of course, Biruni could not finally draw such a conclusion. Only in our time, in the era of the latest science, atomism rejected the emptiness in nature (Tolstov, 1950).

Biruni, apparently, had believed that one of the difficulties of the atomists was the problem of the emergence of a new quality. In this regard, Biruni raised the question of the essence of qualitative transformations. "How do things change and move from one [state] to another: By convergence and 
interpenetration or by change itself? " Some uniqueness of Biruni's atomistic ideas was manifested in his interpretation of this issue in "Monuments of Past Generations", where Biruni, speaking about the "transformation of elements", explains various natural phenomena "by changes in the particles of elements and the transformation of some of them into others."

When studying the views of Biruni, the commonality of his views with the views of another outstanding scientist thinker of the East, Abu Bekr Muhammad ar-Razi, was striking. Ar-Razi adhered to the atomism of Democritus, i.e., teachings about the existence of eternal and unchanging atoms and emptiness. Biruni himself had an ambivalent attitude towards ar-Razi, officially condemned as a heretic. On the one hand, Biruni was forced to call him a heretic and disapproves of some of his alchemical experiments, on the other, he still highly appreciates the scientific activities of ar-Razi (Kraus, 1936).

However, in his philosophical views, unlike ar-Razi, Biruni already rejects the concept of emptiness, the eternal immutability of atoms and thus makes a big step forward in comparison with this scientist. In addition, unlike the latter, which recognized the existence of four elements (earth, fire, water, air), Biruni followed the path of universalizing the elements, proceeding from the idea of the possibility of transforming elements, their transition from one to another. So, unlike Aristotle, whose etherheavenly fire-was regarded as a special independent element, Biruni, already in polemics with Ibn Sina, was inclined to reduce heavenly fire to the essence of earthly fire, which Biruni also considered not as an independent element, but as a kind expression of the rapid movement of atoms and bodies. It was no coincidence that Ibn Sina had accused Biruni of "the opinion of those who considered the elements of one of four, two or three [basic] substances ... like Thales, who saw such a substance in water, Heraclitus, who considered it to be fire ..." Biruni, in his polemic with Ibn Sina, was inclined to consider air as the initial element.

"As for Aristotle," said Ibn Sina, "he believed that none of the four universals [elements] arose from one another and extended this position to their particles" (Faizullaev, 1968).

Biruni himself had written about "heavenly fire": "As for the heat in contact with the interior [of the heavenly sphere], that is, fire, they claim that it is basic and natural, like earth, water and air, because that its shape is round and in our opinion, [fire arises] from heating the air due to the fact that the sphere of the sky rubs against it and hits and touches it in rapid motion ..." (Biruni, 1957a). Biruni "brought down the heavens" by his assertion that the movement of celestial bodies was not circular, as Aristotle believed and saw in this a sign of the special nature of "heavens", but ellipsoidal and the heavenly bodies themselves, according to Biruni, were also have an ellipsoidal shape. By this, he anticipated those important discoveries that were subsequently made by scientists such as Keppler and the achievements of the latest science in the study of the forms of celestial bodies, in particular the Earth.

The tendency to reduce the elements to one basis led Biruni ("India") to the conclusion: The original, single material basis of all elements is water and for Biruni it is not so important to emphasize that water is their basis, as the fact that there is a common material basis of things...

"Therefore, it [water] is a tool and a tool of the creator when he wants to create [anything] out of matter" (Biruni, 1963a).

Biruni had chosen exactly water, since such an understanding could be justified by the saying from the Quran that in the beginning there was Allah and water and further Biruni notes that it does not matter what is meant by the word water.

From his comparison of this provision of the Koran with the materialistic Indian doctrine of the existence of an eternal material principle of water, it became clear that the main thing for him in this case was to justify the existence of such a material principle with the help of the Koran. Naturally, Biruni's naive form of presentation was caused, perhaps, by his desire to diverge as little as possible, at least in form, from the official dogmas of Islam.

\section{Problems of Understanding Nature}

The scientific heritage of Biruni is about 150 works on mathematics, astronomy, geography, mineralogy, astrology, history, ethnography, philology, philosophy.

He was equally well versed in mathematics, astronomy, physics and all other natural sciences. He was particularly distinguished by his contribution to geography, was an excellent historian, an expert in the chronology of various peoples, was an excellent linguist, an expert in the customs and rituals of peoples. For this reason, he was called "Ustod" (teacher, mentor) Richard Fry writes that the contribution of the Iranian peoples to the history of world mathematics is enormous (Frye, 2000).

In this regard, the name of Abu Reikhan Biruni, who was one of the greatest scientists in world history, should be named. Rosenthal and Yarshter (1976) considers Biruni a unique scientist, connecting link between Greek and Indian science.

As a natural philosopher, Biruni inclined towards deism. As a naturalist, he contributed to the expansion of the concept of number, the theory of cubic equations, spherical trigonometry and compiled trigonometric tables. In 1037 Biruni completed the "Canon of Masud" devoted to the general description of the picture of the world. Justifying the six Ptolemaic principles of the universe, 
including the principle of the immobility of the Earth, he made several remarks testifying to the assumption that he allowed the Earth to move around its axis. He supported the theory of egocentrism.

Al-Biruni was so far ahead of his time that his most brilliant discoveries seemed incomprehensible to most of the scholars of his day. He was the first to arrive at an amazingly simple formula for measuring the earth's circumference. He thought It possible that the earth revolved around the sun. He developed the idea that geological eras succeed one another in cycles. "With the passing of time, the sea becomes dry land and dry land the sea," he wrote and on this brilliant hypothesis he based his theory of the earth's geological history The Courier, 1974.

$\mathrm{He}$ recognized the possibility of explaining astronomical phenomena based on a heliocentric picture of the world, but he did not see a practical need for it, since the geocentric system also made it possible to solve all the scientific problems of that time. Based on the study of the chronicles of different peoples, Biruni proposed general principles for making calendars. Being fluent in Arabic, Persian, Greek, Syriac, as well as Sanskrit, this multifaceted scholar contributed to the development of principles for translating natural science terminology from one language into another. Working on the work "India", he translated "Sankhya" (probably, commentaries on "Sankhya-karika") and "Patanjala" ("Yogasutras" of Patanjali) into Arabic. He also transposed into Sanskrit Euclid's Beginnings and Ptolemy's Almagest.

In his work "India" Al-Biruni gave a detailed scientific and critical description of the life, culture and science of Indians, outlined their religious and philosophical systems. Considering the Indian concept of God, he turned to the problem of the root cause of the universe, to the concept of "doer", the acting cause, which in different teachings is represented as God or "nature", "time", "matter". Transposing the classical Sankhya quite accurately, Biruni simultaneously gave his understanding of the theory of cosmic evolution, the doctrine of the soul, its connection with the "subtle body", etc. (Rozenfeld et al., 1973).

Nature, according to Biruni, encompasses all-natural phenomena, the entire surrounding world, subject to certain laws. He had attracted the concept of "natural" when he wanted to emphasize the subordination of this or that phenomenon to certain laws of nature, when this or that phenomenon could be explained and understood based on a scientific study of its essence. Sometimes in our literature, Biruni was mistakenly attributed to materialistic statements of representatives of the Indian philosophical system Swanky: "Matter is the creator", etc. and although Biruni did not even express his attitude to these provisions, the whole spirit of his thoughts about nature and matter, in essence, was similar to them ... Thus, according to Biruni, nature is endowed with "natural strength". In "Monuments» Biruni sympathetically quotes the words of Abu-Mashar: "Nature is strongest." (Biruni, 2014) Biruni often said: "nature creates", or "force doubles its action", etc.

The materialistic idea of Biruni about many worlds was of great importance, which was later put forward by Giordano Bruno. We need to emphasize that, putting forward this idea, Biruni had in mind their material unity. If for Ibn Sina the concept of the unity of the world and its singularity are identical, then Biruni felt that these are different things and on this basis gives an interpretation of the structure of the world, the universe. Therefore, Biruni, speaking about the multitude of worlds, does not violate their material unity, although he does not directly speak about it. His argumentation boiled down to the following: Other worlds can be of a different nature, or the same as this world. If they are of a different nature, then "we did know nature and the four elements only after we ourselves were convinced of their existence."

There he meant that other worlds can have other elements, which, however, just like ours, could be cognized with the help of the senses, i.e., they are material. "It can also be assumed that the other world has the same natural properties as our world, but that only these properties are created in such a way that the directions of movement in it differ from the directions of movement in our world."

However, Biruni considered the system of numerous worlds to converge at one point, i.e., the center of the world-the Earth. But already in the polemic with Ibn Sina Biruni, unlike his opponent, he had noticed a contradiction in Aristotle's position that the Earth is the center of the world and his arguments are not yet based on the analysis of the motion of the planets and the Earth, but proceed from the analysis of the contradictions of the Aristotelian natural philosophy. "If heat spreads from the center (as Aristotle believed-the author), then why does it reach us, proceeding from the sun?"

Biruni did not doubt on another important position of Aristotle, namely about the absolute rest of the Earth. "The fact that the earth is at rest and this is one of the initial truths of astronomy, about which intractable doubts arise." "Moreover, the rotational motion of the Earth does not in the least discredit astronomy and the weight of astronomical phenomena equally proceeds by this motion ..."

He had excellent knowledge of ancient Greek and studied several works by ancient Greek scientists in their original forms; among them there were the Aristotle's Physics, Metaphysics, De Caelo and Meteorology, the works of Euclid and Archimedes, the Almagest of the mathematician and astronomer Ptolemy. 
Thus, we see that Biruni's initial doubts in the Aristotelian and hence in the Ptolemaic system of the world, resulted in the theory of the equivalence of the teachings on the rest and motion of the Earth in the system of other celestial bodies, which was important for the coming triumph of the heliocentric teaching.

Matter in its natural existence could be destroyed. There was no doubt that "natural force" (nature-the author) did not destroy matter when it finds it. "As we have seen, the essence of several Biruni's statements, in particular about water, contains conjectures about the eternal existence of the material principle along with God. In this case, the function of God is reduced, in essence, to the design of matter, i.e., to the creation of the given world from it, the "first impulse". Even though Biruni on this issue significantly had formulated to idealistic religious views about the creation of the world and sometimes took openly idealistic positions, his position in the above statements about God carries materialistic elements.

\section{Discussion}

Al-Biruni's contribution to scientific methodology was the widespread use of the comparative method: "I cite the theories of the Indians as they are and in parallel with them I touch upon the theories of the Greeks to show their mutual closeness," he wrote. At the same time, he referred to Homer, Plato, Aristotle, Galen and other Greek authors, compared Indian and Islamic thought, especially highlighting the teachings of the Sufis as the closest to the Indian theories of Samkhya and yoga. When comparing the customs of different peoples, he mentioned the peculiarities of the life of the Slavs, Tibetans, Khazars, Turks, etc. The transcription system created by Al-Biruni based on the Arabic script largely anticipated the modern system of transmitting Indian words in Urdu. Unfortunately, contemporaries did not understand the significance of the work done by Biruni-"India" was rarely mentioned and quoted by Arab and Persian authors. As the researcher, Al-Biruni emphasized the need for a thorough test of knowledge by experience: Doubts arising in the course of research, "could eliminate experience and re-testing (Mineralogy). In another work ("Geodesy"), he also insists that "the observer should be attentive, carefully review the results of his work, double-check himself." Al-Biruni contrasted empirical knowledge with speculative knowledge, clearly giving preference to the former. As built on speculation, he questioned the cosmic system of Aristotle, from the same positions he criticized Aristotelian and, accordingly, Avicenna's concept of "natural place" and argumentation against the existence of emptiness. The champion of scientific, rational knowledge, logically reasoned and tested by experience, Al-Biruni, was critical of all sorts of pseudosciences, believing that "many mistakes stem from the confusion of scientific and religious issues." Therefore, obliged to engage in astrology, in which "assumptions prevail over reliable knowledge", he limited himself to conclusions based on astronomical research.

The ideas of philosophy were widely spread in the field of literature, acquiring special nuances in it. The genre "adaba" (ethics), a secular trend in the ArabIslamic culture, meaning education through literature of a "commendable way of behavior", was popular not only in the elite, but also in wider circles of society, because in the income-rich, sometimes " light" and piquant form educated, entertained and instructed people. Philosophical ideas were often disseminated in this genre (Faizullaev and Nasyrov, 1970).

Analyzing astronomical, geological and other natural phenomena, Biruni concludes that, speaking about the time of existence of the Earth and other celestial bodies, "the calculator is not forbidden to talk about thousands of millions of years". Biruni was one of the first to analyze various geological phenomena and, based on this, comes to very original conclusions. Even the Pakistani Scientist S. Kh. Baraniy, who had believed that Islam and were the same for Biruni wrote: "He (Biruni-the author) had considered the idea of the eternity of the world. He stands on a purely scientific point of view when he refers on the changes that the Earth has undergone for many centuries, leaving traces of fauna and flora in the layers of mountains and deserts, similar to those recent changes that each of us sees in his time and from reliable stories."

Consequently, Biruni concluded that "...like a modern geologist, Biruni considered it necessary for a long time for the Earth to go through all these enormous changes." (Biruni, 1957b).

Taking into consideration Biruni further outlined the content of Biruni's book: "The next subject of presentation is the evolution of the globe under the influence of natural forces. Here he supports the theory of Aristotle, expressing his own judgments that "in earlier periods of time, the Earth was in a liquid state."

These very vivid philosophical arguments of Biruni had been analyzed by the English scientist (Krenkov, 1964).

Biruni, noting that the scriptures and various religious sources gave extremely contradictory information about the time of the existence of the Earth, believes that the main criterion for determining its age was the scientific studied of various phenomena occurring on it.

The keen eye of such an outstanding natural scientist as Biruni could not help but notice that the idea of nature as something frozen and unchanging contradicts what could be observed in the surrounding world. This view of nature as something constantly moving, changing, Biruni conducted more consistently and systematically than his great contemporary Ibn Sina.

Biruni was more decisive in his conclusions arising from experience and observations. The latter gave Biruni the opportunity to sometimes drew even more radical 
philosophical conclusions and find contradictions in Ibn Sina's position on certain issues.

In Biruni's statement about changes on the Earth, it is interesting to note that events "occur either immediately or sequentially." This subtle observation of Biruni had been concerned the dialectical nature of the development of various processes on earth, the alternation of spasmodic development and gradual evolution.

\section{Conclusion}

Thus, Biruni considered possible the spontaneous generation of various small insects and animals from inanimate matter and argues that this requires certain conditions, namely, when the moisture is affected by "moderate heat", etc. This comes into direct agreement with the provisions of religion that all kinds of animals and plants were created by God, that only God can "breathe" life into inanimate matter.

Even the "holy of holies" of previous scientists and philosophers-the heavenly sphere-according to Biruni, undergone certain changes: "Once created, they [stars, cycles of stars] decreased [in magnitude], increasing at the same time in number."

However, contradicting himself, Biruni noted that "... nature preserves genera and species as they are."

Biruni in his works often spoke about the theory of the cyclical development of the world. This teaching, if strictly adhered to, can lead to the conclusion that the existence of the world is infinite and, even though Biruni proceeded from the recognition of the creation of the world by God, he fully approves of this theory.

So, in "India" he speaks about it as follows: "... Their (Indians-the author) ideas about the cyclical nature of repeated periods of time correspond to what is observed in reality."

Thus, an examination of Biruni's philosophical views shows how strong the materialistic tendency is in them, despite the idealism of the starting positions. Biruni's worldview should be studied in its living integrity, in all its contradictions and complexity and not by the one-sided highlighting of its weaknesses.

\section{Acknowledgment}

I thank Bethany Ware, Ms. Zunaira (Editorial Office Science Publications) and Iram Saddique (Customer Support) for the great help. They taught me how to write and format a scientific article correctly. Thanks to their advice and practical help, I was able to learn more about the rules and etiquette of the Journal.

\section{Ethics}

There is no conflict of interest in the article. Copyright is not violated. All ethical rules have been followed.

\section{References}

Arthur Upham Pope. (1951). AI-Biruni as a thinker',' AlBiruniy commemoration Volume. http://beruni.uz/en

Biruni, A. R. (1957a). Selected works. Vol. I. Monuments of past generations/A. Biruni. Tashkent: Publish. Academy of Science UzSSR. http://beruni.uz/en.

Biruni, S. H. (1957b). Kitabut-Tahdid (An unpublished masterpiece of Al Biruni on astronomical geography). Islamic Culture, 31, 165-77.

Biruni, A. R. (1963a). Selected Works. Tashkent, Publishing House of the Academy of Sciences of the Uzbek SSR. http://beruni.uz/en

Biruni. (1963b). A treatise on the determination of chords in a circle using a broken line inscribed in it, "From the history of science and technology in the countries of the East. http://beruni.uz/en

Biruni, A. R. (2014). Monuments of the past generations. Selected works. Tashkent: Fan. http://beruni.uz/en

Faizullaev, A. (1962). On some of the simplest manifestations of self-motion of matter. Dissertation for the degree of candidate of philosophical sciences, Tashkent. http://beruni.uz/en

Faizullaev, A. F. (1968). Questions of contradictory movements in the philosophical discussion of Beruni and Ibn Sina, "Social Sciences in Uzbekistan". http://beruni.uz/en

Faizullaev, A. F., \& Nasyrov, R. N. (1970). Questions of truth in the philosophical discussion of Biruni and Ibn Sina. - Social sciences in Uzbekistan. http://beruni.uz/en

Frye, R. N. (2000). The Golden age of Persia. London: Phoenix Press. ISBN-10: 1842120115.

Kraus, P. (1936). Epitre de Biruni contenant la Repertoire des Ouvrages de Mull. b. Zakarlya ar-Razi publee par,

Paris. https://uzjournals.edu.uz/cgi/viewcontent.cgi?article $=1691 \&$ context $=$ namdu

Krenkov, S. F. (1964). Biruni and the miss Sultan Fatih. N 3386, 'Al-Iil-runi commemoration volume'.

Marx, K. (1962). Engels Works. https://www.bard.edu/library/arendt/pdfs/MarxEngel s-SelectedWorks.pdf

Nasr, S. H. (1993). An introduction to Islamic cosmological doctrines: conceptions of nature and methods used for its study by the Ikhwan al-DafaD, al-Bïrûnï and Ibn Sina", 2nd edition, Revised. SUNY press, $1993 . \quad$ P. 111. https://philpapers.org/rec/NASAIT

Rosenthal, F., \& Yarshter, E. (1976). Al-Biruni between Greece and India. In Biruni Symposium, Ehsan Yarshater, ed (Vol. 5). https://philarchive.org/archive/BOSBAR 
Rozenfeld, B.A., Rozhanskaya, M. M., \& Sokolovskaya, Z. K. (1973). Abu-r-Reikhan Al-Biruni (973-1048) M.: Nauka. http://pyrkovprofessor.ru/default.aspx?tabid=186\&ArticleId=309

Semenov, A. A. (1950). Biruni is an outstanding scientist of the Middle Ages. Sat. articles " Biruni - the great scientist of the Middle Ages", Tashkent, Publishing House of the Academy of Sciences of the Uzbek SSR, 1950, p. 29. http://beruni.uz/en

Sparavigna, A. C. (2013). The science of Al-Biruni. arXiv preprint arXiv:1312.7288. https://arxiv.org/abs/1312.7288

Tolstov, S. P. (1950). Biruni and his Time. Biruni (collection).-M.

Sprenger, A. (1986). Al Biruni's India. Zeitschrift der Deutchen Morgenlendischen geselschaften, Hefte II, pp. 329-335. http://beruni.uz/en
Usmanov, M. A. (1973). The problem of religion in the worldview of Biruni//Biruni. Collection of articles for the 1000th anniversary of his birth. Tashkent. http://beruni.uz/en

Uzbek SSR. (1957). Materials on the history of progressive socio-philosophical thought in Uzbekistan. Tashkent, Publishing House of the Academy of Sciences of the Uzbek SSR. http://beruni.uz/en

Zakhidov, P. Y. (1950a). Biruni as a thinker. Sat. " Biruni", M. - L. http://beruni.uz/en

Zakhidov, V. Y. (1950b). Biruni as a thinker, Sat. articles " Biruni", M. - L., Publishing house of the Academy of Sciences of the USSR. http://beruni.uz/en 